\title{
A Guide to Submitting a Successful NIH S10 Shared Instrumentation Grant Application
}

\author{
Frank P. Macaluso ${ }^{1}$ \\ ${ }^{1}$ Analytical Imaging Facility, Albert Einstein College of Medicine, Bronx, USA.
}

A major responsibility of shared facility directors is to identify, support and provide current technology. One mechanism to acquire new technology is through the National Institutes of Health, Office of Research Infrastructure Programs' S10 Instrumentation Grant Programs [1]. These programs support the purchase of state-of-the-art commercially available instruments to enhance research of NIH-funded investigators. There are three programs available 1) Shared Instrumentation Grant (SIG) Program, 2) Shared Instrumentation for Animal Research (SIFAR) Grant Program and 3) High-End Instrumentation (HEI) Grant Program. This paper will specifically address the SIG award [2]. To be eligible for an S10 award, an institution must identify three or more Principal Investigators with active NIH research awards who demonstrate the substantial need for the requested instrument. The minimum award is $\$ 50,000$ and the maximum award is $\$ 600,000$.

The first step in deciding to apply for the SIG award is identifying the need for a particular technology. The science should drive the choice of technology. Needed new technology should be identified in conjunction with active users of a shared resource, based on recent publications. Identifying a group (three or more) of Principle Investigators who require this technology to advance their research programs that have current NIH funding is essential. It is beneficial to have more than three Major Users because having a larger Major User Group emphasizes the need for the requested technology and enhances the cost saving component of the SIG Program.

The SIG program is an annual award. The deadline for submission is at the end of May. One should begin SIG planning early, typically before January 1 of the submission year. By January a review of the technical specifications of all the instruments under consideration should be complete. It is advisable to research all major instruments on the market that offer a certain technology and to compare and contrast the advantages and disadvantages of each instrument to narrow down the best choice for your particular Major User group as part of your grant narrative. Although preliminary data is not required, including preliminary data in the Major User Research Projects demonstrates necessity and feasibility to the reviewers. It is advisable to prepare a set of demo samples that represents the requirements of the Major Users and collect data from each instrument using the same samples. This makes instrument comparison straightforward. Keep in mind the time and effort it will take to coordinate instrumentation demonstrations with several different vendors. This may include on site demonstrations as well as travel to other locations to test instruments.

Demonstration of technical expertise is critical. Shared Facilities typically have this requirement covered because the director and staff are experts in their respective areas. Note the strengths of the facility director in your application. Include the technical staff as well if appropriate. If the technology is novel, explain how expertise will be acquired by the director and disseminated to the staff and Major Users.

When you begin to write, it is imperative that the instructions are followed exactly. The application is complex with many items that must be included. Applications that do not follow the instructions may 
not be reviewed. Page limits must be strictly observed. Operational and business plans must be clearly presented. Address issues such as scheduling, maintenance, supplies, training and billing. Shared facilities often have these items already in place for existing instrumentation. Advise the reviewers if an operational plan is already in place and the new instrument will be managed in the same manner, if appropriate.

Institutional support is a key component. The Dean or other institutional official must provide a letter of support, committing to fund renovations, service contracts or personnel over an extended period, even the projected life of the instrument.

The NIH S10 Instrumentation Program is an ideal mechanism for Shared Facilities to acquire new technology, to replace and update aging instrumentation or remain current as mature technologies progress. Clearly demonstrate the need scientifically and detail how the shared facility will provide infrastructure support for operation, training and maintenance to submit a successful application [3].

[1] The S10 Instrumentation Programs, https://orip.nih.gov/construction-and-instruments/s10-instrumentation-programs

[2] S10 Biomedical Research Support Shared Instrumentation Grants (2018), https:/grants.nih.gov/grants/guide/pa-files/PAR-18-600.html

[3] Dr. Vera DesMarais is thanked for her many useful discussions and contributions to this work.

\begin{tabular}{|l|l|}
\hline Suggested timeline & Task \\
\hline September - December & $\begin{array}{l}\text { Identify the technology } \\
\text { Identify NIH-funded Major Users } \\
\text { Compile a list of vendors }\end{array}$ \\
\hline January & $\begin{array}{l}\text { Obtain Institutional approval } \\
\text { Prepare demo samples }\end{array}$ \\
\hline January - February & $\begin{array}{l}\text { Demo selected instruments } \\
\text { Analyze the demo data }\end{array}$ \\
\hline March & $\begin{array}{l}\text { Select the appropriate instrument } \\
\text { Write Technical Justification } \\
\text { Write Business Plan } \\
\text { Collect Major User NIH Biosketch }\end{array}$ \\
\hline April & Review Major User projects \\
\hline May & $\begin{array}{l}\text { Review assembled application } \\
\text { Submit grant application }\end{array}$ \\
\hline
\end{tabular}

Table 1. Suggested timeline for preparing a successful SIG submission 